\title{
Investigation for Paediatric Cushing's Syndrome Using Twenty-Four-Hour Urinary Free Cortisol Determination
}

\author{
Lucy Shapiro $^{a}$ Shezan Elahi ${ }^{a} \quad$ Fiona Riddoch $^{\mathrm{b}}$ Leslie A. Perry ${ }^{c}$ Lee Martin ${ }^{\mathrm{a}}$ \\ Scott A. Akker ${ }^{a}$ John P. Monson ${ }^{a}$ William M. Drake ${ }^{a}$ Ashley B. Grossman ${ }^{d}$ \\ Martin O. Savage ${ }^{a} \quad$ Helen L. Storr ${ }^{a}$ \\ ${ }^{a}$ Centre for Endocrinology, William Harvey Research Institute, Barts and the London School of Medicine and \\ Dentistry, Queen Mary University of London, and ${ }^{b}$ Department of Clinical Biochemistry, Barts Health NHS \\ Trust, London, 'Pathology Department, Croydon Health Services, Croydon, and d Oxford Centre for Diabetes, \\ Endocrinology and Metabolism, University of Oxford, Oxford, UK
}

\section{Key Words}

Cushing's syndrome · Urinary free cortisol · Children .

Diagnosis $\cdot$ Screening

\begin{abstract}
Objective: Paediatric Cushing's syndrome (CS) remains a challenge to diagnose and exclude. We assessed the accuracy of 24-hour urinary free cortisol (UFC) determination in children referred for suspected CS. Design: We conducted a retrospective study of paediatric patients referred to our centre with suspected CS between 1982 and 2014. Patients: Of 66 subjects (mean age 12.9 years; range 4.4-16.9), there were 47 cases of CS (29 males), which included Cushing's disease (CD; 39 patients, 25 males), primary pigmented nodular adrenocortical disease (8 patients, 4 males) and 19 'controls' (6 males) in whom the diagnosis of CS was excluded. Measurements: The subjects had between one and five 24hour UFC collections analysed by radioimmunoassay, chemiluminescent immunoassay or liquid chromatographymass spectrometry. The data were normalised, corrected for body surface area $\left(\mathrm{m}^{2}\right)$ and assessed using receiver operat-
\end{abstract}

\section{KARGER}

(c) 2016 S. Karger AG, Basel

E-Mail karger@karger.com

www.karger.com/hrp ing characteristic analysis and an independent two-tailed $t$ test. Results: The diagnostic accuracy of 24-hour UFC for CS was excellent (area under the curve $0.98,95 \% \mathrm{Cl} 0.946-1.00$, sensitivity $89 \%$, specificity $100 \%)$. Conclusions: Twentyfour-hour UFC is a reliable and practical investigation with high diagnostic accuracy for paediatric CS. However, further investigations may be required if the UFC is normal but there is a high diagnostic suspicion of CS. $\quad$ ○ $2016 \mathrm{~S}$. Karger AG, Basel

\section{Introduction}

Endogenous Cushing's syndrome (CS) is extremely rare in childhood [1] and is characterised by a deceleration in height velocity in association with significant weight gain. Despite these hallmark features, CS may be difficult to recognise because of its very low incidence in the paediatric population and its insidious onset in many individuals $[1,2]$. The increasing incidence of paediatric obesity is well recognised [3], and underlying pathological causes need to be excluded. Diagnosing CS in children 
is particularly challenging as its presenting features are variable and can be subtle, especially in young patients [4]. As a result, there is often a significant delay in diagnosing CS in the paediatric age range [5], which can result in significant morbidity, mortality and a reduction in quality of life [6-9]. Therefore, it is important to have a readily available and robust investigation to accurately identify cases of CS amongst children with unexplained weight gain.

Published diagnostic guidelines for CS [10-13] are heavily based upon adult studies, as data in children with this disorder are scarce. However, there are important differences between paediatric and adult CS. Pubertal delay or arrest is frequently seen in paediatric CS patients, caused by suppression of the hypothalamo-pituitary-gonadal axis by hypercortisolaemia. Frequently reported symptoms and signs in childhood include a change in facial appearance, lethargy and emotional lability, whereas in adults, headaches, hypertension (HTN), striae and acne are common additional findings. There are also recognised aetiological differences between adult and paediatric CS groups; for example, pituitary macroadenomas are much less common in paediatric patients [5] and ectopic adrenocorticotropic hormone (ACTH)-secreting tumours are exceptionally rare $[14,15]$.

Existing investigations for the diagnosis and differential diagnosis of CS include 24-hour urinary free cortisol (UFC) determination, 09.00 plasma ACTH, sleeping 00.00 cortisol, late-night salivary cortisol, low- and highdose dexamethasone suppression tests (LDDST and HDDST), corticotrophin-releasing hormone (CRH) test, pituitary MRI, abdominal imaging and bilateral simultaneous inferior petrosal sinus sampling for ACTH(BSIPSS) [16-19]. The 24-hour UFC measurement has been widely used as an investigation for hypercortisolaemia and is reported to have a sensitivity of $>90 \%$ in adult populations $[20,21]$. Twenty-four-hour UFC excretion is not affected by changes in cortisol-binding globulin, which was reported to be a potential disadvantage in the measurement of serum cortisol [6]. The Endocrine Society recommended 24-hour UFC as an initial investigation for CS [10]; however, more recent studies have shown that its value in adults with suspected CS is limited because of high variability, particularly in cases of subclinical or cyclical Cushing's disease (CD) [22, 23].

In paediatric practice, controversy regarding the value of UFC measurement still exists. Additionally, the $88 \%$ reported sensitivity of UFC determination for children with CS is slightly lower in the paediatric than adult age range [17]. It has also been suggested that increased UFC
Table 1. Diagnostic characteristics

\begin{tabular}{llll}
\hline Patient group & CD & PPNAD & Controls \\
\hline $\begin{array}{l}\text { Patients, } \mathrm{n} \\
\text { Males }\end{array}$ & 39 & 8 & 19 \\
\hline Mean age, years & 25 & 4 & 6 \\
$\quad$ Range & $5.7-16.9$ & $10.5-16.9$ & $4.4-15.7$ \\
\hline
\end{tabular}

excretion may not be a consistent finding in paediatric CS, and therefore serial measurements are necessary to rule out this diagnosis [17].

The objective of the present study was to assess the accuracy of 24-hour UFC excretion in paediatric patients referred for evaluation of suspected CS in our centre. We also evaluated 24-hour UFC levels in two different diagnostic groups, $\mathrm{CD}$ and primary pigmented nodular adrenocortical disease (PPNAD), and assessed the effect of gender and severity of CS on UFC concentrations.

\section{Materials and Methods}

\section{Patients and Data Collection}

A retrospective review of paediatric cases with suspected CS referred to Barts Health NHS Trust between 1982 and 2014 was undertaken. The series comprised 66 subjects: 39 cases of CD, 8 with CS due to PPNAD and 19 subjects in whom CS was subsequently excluded and who served as a control group. The patient characteristics are shown in table 1.

\section{Symptoms and Signs}

The clinical features of the patients at diagnosis are shown in tables 2 and 3. The mean duration of symptoms was 2 years $(0.25-$ $5.0)$ before diagnosis of CS and 1.7 years $(0.4-5.0)$ before CS was excluded in the control group. HTN in the paediatric subjects was defined as a diastolic or systolic blood pressure $>95$ th centile for age and sex on more than two occasions [24].

\section{Diagnosis of CS}

All subjects (total 66 patients; 35 males), had a mean age of 12.9 years; (range 4.4-16.9), clinical features suggestive of hypercortisolaemia and diagnostic tests were performed according to published paediatric and adult endocrinology protocols [25-28] (table 4). These included 09.00 plasma ACTH, sleeping 00.00 cortisol, LDDST, CRH testing, radiological investigations (pituitary MRI or adrenal imaging) and BSIPSS. CS was excluded in all subjects in the control group (total 19 patients; 6 males), mean age 11.5 years (range 4.4-15.7), by at least one undetectable ( $<50 \mathrm{nmol} / \mathrm{l})$ sleeping midnight serum cortisol with suppression of serum cortisol to $<50 \mathrm{nmol} / \mathrm{l}$ during a LDDST (table 4 ) and by subsequent clinical follow-up.
Shapiro et al. 
Table 2. Height SDS and BMI SDS in the different diagnostic groups

\begin{tabular}{|c|c|c|c|c|c|c|c|c|}
\hline & \multicolumn{4}{|c|}{ Mean height SDS } & \multicolumn{4}{|c|}{ Mean BMI SDS } \\
\hline & mean & range & $\mathrm{p}$ value & $\begin{array}{l}95 \% \text { CI vs. } \\
\text { control }\end{array}$ & mean & range & $\mathrm{p}$ value & $\begin{array}{l}95 \% \text { CI } \\
\text { vs. control }\end{array}$ \\
\hline $\mathrm{CD}(\mathrm{n}=39)$ & -1.7 & -5 to 1.2 & $<0.01$ & 1.18 to 2.7 & 3.0 & -0.4 to 9.2 & 0.5 & 1.08 to 0.49 \\
\hline $\operatorname{PPNAD}(\mathrm{n}=8)$ & -0.62 & -2.5 to 0.44 & 0.1 & -2 to 2.96 & 2.05 & -0.6 to 4.6 & 0.3 & 2.2 to 0.15 \\
\hline Controls $(n=19)$ & 0.2 & -3.4 to 2.3 & & & 3.2 & 2.8 to 4.8 & & \\
\hline
\end{tabular}

p values represent comparison of the group (CD, PPNAD) and controls.

Table 3. Clinical features of patients in the different diagnostic groups

\begin{tabular}{lllll}
\hline $\begin{array}{l}\text { Clinical symptom } \\
\text { or sign }\end{array}$ & Controls & PPNAD & CD & Total CS \\
\hline Hypertension & $13(16)$ & $43(7)$ & $51(39)$ & $50(46)$ \\
Striae & $37(19)$ & $50(6)$ & $54(37)$ & $53(43)$ \\
Headaches & $37(19)$ & $43(7)$ & $58(38)$ & $56(45)$ \\
Hirsutism & $26(19)$ & $50(8)$ & $59(39)$ & $57(47)$ \\
\hline
\end{tabular}

Values are expressed as \% affected of the total number for whom data are available (n).

\section{Auxology and Puberty Staging}

Height and weight were measured in all patients using standardised techniques [29]. Puberty was assessed using Tanner's criteria $[30,31]$.

\section{Twenty-Four-Hour UFC Collection}

All patients had one to four completed 24-hour UFC collections performed in the hospital. Some of the 19 control subjects had UFC collections on non-consecutive days. The mean value was calculated for those having more than one collection and used in further analysis.

\section{Assays}

Twenty-four-hour UFC was measured by one of three methods, reflecting the change in laboratory practice over the 30-year period. Until 1995, in-house radioimmunoassay was used (normal value $<240 \mathrm{nmol} / 24 \mathrm{~h}$ ). Between 1995 and February 2012, Siemens 2000 immunoassay was used (normal range 40-340 nmol/24 h). Since February 2012, a liquid chromatography-mass spectrometry method has been used (normal value $<124 \mathrm{nmol} / 24 \mathrm{~h}$ ). To account for the differences in the reference ranges of the 3 assays, each data point has been normalised to generate unitless values, as described elsewhere [32]. The patient's 24-hour UFC value was then expressed as a fraction of the upper limit of the assay's normal range. Therefore, values below $<1.0$ are within the normal range, and values $>1.0$ are higher than the upper limit of the assay reference range. Twenty-four-hour UFC values were then corrected for body surface area $\left(\mathrm{BSA}, \mathrm{m}^{2}\right)$.

Twenty-Four-Hour UFC in Paediatric Cushing's Syndrome
Table 4. Diagnostic features of CS

\begin{tabular}{|c|c|c|}
\hline & $\mathrm{CD}$ & PPNAD \\
\hline Patients, $\mathrm{n}$ & 39 & 8 \\
\hline Male & 25 & 4 \\
\hline Mean age, years & 11.7 & 12.9 \\
\hline Range & $5.7-16.9$ & $10.5-16.9$ \\
\hline $09.00 \mathrm{~h}$ plasma $\mathrm{ACTH}, \mathrm{ng} / \mathrm{l}$ & $10-50$ & $<10$ \\
\hline \multicolumn{3}{|l|}{ Sleeping $0.00 \mathrm{~h}$ cortisol, $\mathrm{nmol} / \mathrm{l}$} \\
\hline Mean & 530.3 & 507.9 \\
\hline Range & $146-1,377$ & $400-622$ \\
\hline \multicolumn{3}{|l|}{ Serum cortisol at $48 \mathrm{~h}$ in LDDST } \\
\hline \multicolumn{3}{|l|}{ (0.5 mg 6 hourly for $48 \mathrm{~h}), \mathrm{nmol} / \mathrm{l}$} \\
\hline Mean & 325.2 & 519.6 \\
\hline Range & $22-1,063$ & $400-622$ \\
\hline \multicolumn{3}{|c|}{$\begin{array}{l}\% \text { increase in serum cortisol from } \\
\text { baseline during CRH test }(1 \mu \mathrm{g} / \mathrm{kg} \text { i.v. })\end{array}$} \\
\hline Mean & 207 & 1.3 \\
\hline Range & $34-823$ & $0-6$ \\
\hline \multicolumn{3}{|l|}{ BSIPSS } \\
\hline Central ACTH secretion & & not \\
\hline confirmed in 28 patients, $\%$ & 72 & indicated \\
\hline Mean central to peripheral & & \\
\hline ACTH ratio after CRH 6.8 & $1-34.6$ & \\
\hline
\end{tabular}

\section{Statistical Analysis}

Data were analysed by SPSS (version 22; IBM Corp., Armonk, N.Y., USA). All values were assessed against the corresponding normal range and included in calculating the diagnostic accuracy of the 24-hour UFC as a test for CS. The diagnostic accuracy was depicted by the area under the curve (AUC) values from receiver operating characteristics (ROC) analysis performed against the control group. The AUC quantifies the overall ability of the test to discriminate between those individuals with the disease and those without the disease. A perfect test, i.e. one that has zero false positives and zero false negatives, has an area of 1.00. The results of the ROC analyses were classified according to the AUC values as fail (AUC $=0.50-0.59)$, poor $(0.60-0.69)$, moderate $(0.70-0.79)$, good (0.80-0.89) and excellent (0.90-1.00). An independent two-tailed $t$ test was performed to calculate the differences between the mean 24-hour UFC values. 


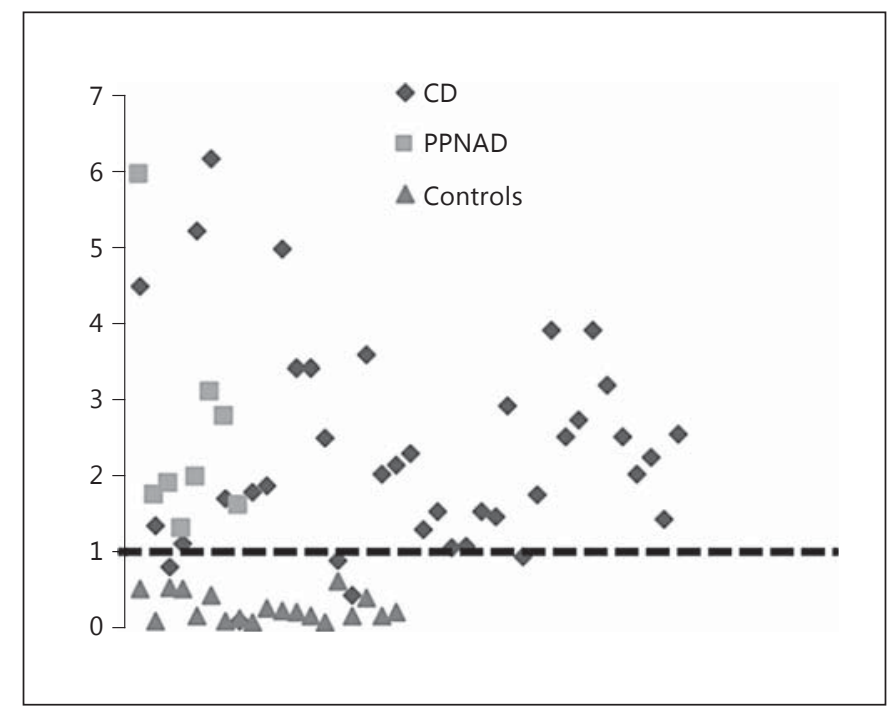

Fig. 1. Twenty-four-hour UFC/BSA in all patient groups.

Statement of Ethics

Clinical informed consent was obtained from the patients and/ or their parents and, as part of an ongoing prospective audit into the investigation and outcome of patients with CS, institutional review board permission was granted for the release of anonymised data for publication.

\section{Results}

\section{Twenty-Four-Hour UFC Measurements in the CS} Group

In the subjects with CS, 53\% $(\mathrm{n}=25)$ had one, $30 \%$ $(\mathrm{n}=14)$ had two, 13\% $(\mathrm{n}=6)$ had three and $4 \%(\mathrm{n}=2)$ had four 24-hour UFC collections. In the control group, $11 \%(n=2)$ had one, $47 \%(n=9)$ had two, $31 \%(n=6)$ had three and $11 \%(n=2)$ had five collections. Twentyfour-hour UFC/BSA values for all patient groups are shown in figure 1 . When corrected for BSA, the diagnostic accuracy for CS, as measured by the AUC was high $(0.98,95 \%$ CI $0.946-1.00)$, with a sensitivity and specificity for CS being 89 and 100\%, respectively.

Five patients with $\mathrm{CD}$ had a normal mean 24-hour UFC/BSA ratio. All but one had typical Cushingoid phenotypes. Patient 1 had CD with cyclical hypercortisolaemia. She was an 11.9-year-old female with height -2.0 SDS, BMI 2.5 SDS, excessive virilisation, striae and headaches. She had a pituitary macroadenoma, and her UFC/ BSA ratios were $0.17,0.06$ and 0.06 (mean 0.10). Patient 2 was a 15.6-year-old pubertal male (Tanner stages pubic hair 4, genitalia 4, testes $12 \mathrm{ml}$ ) with striae, height -1.1 SDS and weight 3 SDS. His UFC/BSA ratios were 0.33 and 0.52 (mean 0.42 ). Patient 3 , a male aged 6.4 years, was excessively virilised (Tanner stages pubic hair 2, genitalia 2, testes $2 \mathrm{ml}$ ), with height -1.6 SDS, BMI 5.1 SDS and UFC/ BSA ratios of $1.00,0.68$ and 0.73 (mean 0.8). Patient 4, a female aged 13.2 years, had Cushingoid appearance, height -2.8 SDS, BMI 2.3 SDS, HTN, striae, headaches and UFC/BSA ratios of 0.86 and 0.92 (mean 0.89). Patient 5, a 13.2-year-old male, had normal height (0.1 SDS), BMI $(-0.4$ SDS) and normal puberty (Tanner stages genitalia 3, pubic hair 2, axillary hair 2, testes 8, $10 \mathrm{ml}$ ) and HTN with a single UFC/BSA ratio of 0.94 .

\section{Twenty-Four-Hour UFC Measurements in the Control} Group

In the control group, all subjects had mean 24-hour UFC concentrations within the normal range when corrected for BSA, demonstrating a specificity of $100 \%$.

\section{Twenty-Four-Hour UFC Measurements in CD versus} PPNAD

A comparison of 24-hour UFC measurements in patients with CD and PPNAD was undertaken. When adjusted for BSA, no significant difference was found; CD mean 2.32, PPNAD mean 2.53, p value $0.7,95 \% \mathrm{CI}-1.28$ to 0.88 .

\section{Discussion}

In the context of the increasing incidence of paediatric obesity and the associated increase in the number of children referred with possible CS, it is useful to have a simple, reliable, non-invasive and inexpensive investigation, which provides information relevant to hypercortisolaemia. The advantage of 24-hour UFC determination is that the collections can be arranged at home or locally without the need for referral to a tertiary unit.

In contrast to the adult CS literature, few studies focus on investigations in the paediatric age range. We report the utility of 24-hour UFC determination in paediatric patients referred with possible CS. Our results demonstrate a high sensitivity and specificity of 24-hour UFC for the detection of hypercortisolaemia. This confirms a previous report, which showed sensitivity and specificity of 24hour UFC/BSA values of 88 and 90\%, respectively, in paediatric CS, and collections over more than 1 day, improving accuracy [17]. This suggests that measuring 24-hour UFC is a useful non-invasive test that helps differentiating 
CS from simple obesity in paediatric practice. We found higher 24-hour UFC concentrations in the subjects with PPNAD compared to those with CD, but the difference was not significant when adjusted for BSA. This has not previously been examined in adults or children with CS. Our results emphasise the need to take BSA into account when analysing 24-hour UFC concentrations.

The patient with cyclical CS had normal 24-hour UFC. These results are in agreement with published adult studies, which suggest that 24-hour UFC might be a suboptimal test in mild disease, cyclical CS and in patients with renal impairment [23]. UFC measurements may be negative or borderline when the hypercortisolaemia is mild or periodic. These borderline abnormalities in cortisol hypersecretion appear to be more common in the adult population, and UFC measurements are less useful in this clinical situation. If 24-hour UFC is repeatedly normal but clinical suspicion remains, there is a small chance that the CS result is false positive, and other investigations should be undertaken. Measurement of midnight salivary cortisol may be a more appropriate alternative screening test for these difficult cases [33].

The predictive power of the 24-hour UFC measurements may be further improved by collecting urine over 3 consecutive days [17] since increased UFC excretion may not be a consistent finding in children [17]. Therefore, serial measurements are necessary to confidently exclude paediatric CS. Adult studies have also demonstrated that 24-hour UFC values can be variable, and ideally a minimum of three measurements need to be performed if the first result is normal and the clinical suspicion of CS is high [34]. An Endocrine Society Clinical Practice Guideline recommends at least two UFC measurements as an initial investigation for CS [10]. Patients also need to avoid excessive fluid intake, and the complete urine collection volume should be sent for analysis [23]. Urine collections can be particularly challenging in young children. Consistent with this, we show that $41 \%$ of all children (CS and controls) produced only one 24 -hour UFC collection.

Our study has obvious limitations; in particular the relatively short follow-up period for the control cases. Whilst we cannot be certain that there are no 'missed' cases of CS in the control group, a combination of undetectable midnight cortisol level with suppression of cortisol on LDDST and subsequent clinical follow-up allowed us to confidently exclude CS. Our results support the contribution of 24-hour UFC to the diagnosis in children with overt features of CS. The increasing incidence of obesity in the paediatric population is likely to lead to more investigations of patients with less extreme clinical features in general paediatric clinics. In conclusion, our results suggest that the measurement of 24-hour UFC has a high diagnostic accuracy and may contribute to the diagnosis or exclusion of CS in the paediatric age range.

\section{Disclosure Statement}

The authors declare that they have no conflicts of interest to disclose.

\section{References}

$>1$ Chan LF, Storr HL, Grossman AB, Savage MO: Pediatric Cushing's syndrome: clinical features, diagnosis, and treatment. Arq Bras Endocrinol Metabol 2007;51:1261-1271.

-2 Kanter AS, Diallo AO, Jane JA Jr, Sheehan JP, Asthagiri AR, Oskouian RJ, et al: Single-center experience with pediatric Cushing's disease. J Neurosurg 2005;103(suppl 5):413-420.

$>3$ Lissau I: Overweight and obesity epidemic among children. Answer from European countries. Int J Obes Relat Metab Disord 2004;28(suppl 3):S10-S15.

4 Biller BM, Grossman AB, Stewart PM, Melmed S, Bertagna X, Bertherat J, et al: Treatment of adrenocorticotropin-dependent Cushing's syndrome: a consensus statement. J Clin Endocrinol Metab 2008;93:24542462.
-5 Storr HL, Alexandraki KI, Martin L, Isidori AM, Kaltsas GA, Monson JP, et al: Comparisons in the epidemiology, diagnostic features and cure rate by transsphenoidal surgery between paediatric and adult-onset Cushing's disease. Eur J Endocrinol 2011;164:667-674.

-6 Magiakou MA, Mastorakos G, Oldfield EH, Gomez MT, Doppman JL, Cutler GB Jr, et al: Cushing's syndrome in children and adolescents. Presentation, diagnosis, and therapy. N Engl J Med 1994;331:629-636.

7 Shah NS, George J, Acharya SV, Lila AR, Sarathi V, Bandgar TR, et al: Cushing disease in children and adolescents: twenty years' experience in a tertiary care center in India. Endocr Pract 2011;17:369-376.

$>8$ Stratakis CA: Cushing syndrome in pediatrics. Endocrinol Metab Clin North Am 2012; 41:793-803.

-9 Bista B, Beck N: Cushing syndrome. Indian J Pediatr 2014;81:158-164.
10 Nieman LK, Biller BM, Findling JW, NewellPrice J, Savage MO, Stewart PM, et al: The diagnosis of Cushing's syndrome: an Endocrine Society Clinical Practice Guideline. J Clin Endocrinol Metabolism 2008;93:1526-1540.

11 Guignat L, Bertherat J: The diagnosis of Cushing's syndrome: an Endocrine Society Clinical Practice Guideline: commentary from a European perspective. Eur J Endocrinol 2010;163: 9-13.

-12 Kageyama K, Oki Y, Sakihara S, Nigawara T, Terui K, Suda T: Evaluation of the diagnostic criteria for Cushing's disease in Japan. Endocr J 2013;60:127-135.

13 Lila AR, Sarathi V, Jagtap VS, Bandgar T, Menon P, Shah NS: Cushing's syndrome: stepwise approach to diagnosis. Indian J Endocrinol Metab 2011;15(suppl 4):S317-S321.
Twenty-Four-Hour UFC in Paediatric Cushing's Syndrome
Horm Res Paediatr 2016;86:21-26 DOI: $10.1159 / 000446913$ 
14 Invitti C, Pecori Giraldi F, de Martin M, Cavagnini F: Diagnosis and management of Cushing's syndrome: results of an Italian multicentre study. Study Group of the Italian Society of Endocrinology on the Pathophysiology of the Hypothalamic-Pituitary-Adrenal Axis. J Clin Endocrinol Metab 1999;84:440448.

15 Joshi SM, Hewitt RJ, Storr HL, Rezajooi K, Ellamushi $\mathrm{H}$, Grossman $A B$, et al: Cushing's disease in children and adolescents: 20 years of experience in a single neurosurgical center. Neurosurgery 2005;57:281-285; discussion 285.

16 Elamin MB, Murad MH, Mullan R, Erickson D, Harris K, Nadeem S, et al: Accuracy of diagnostic tests for Cushing's syndrome: a systematic review and metaanalyses. J Clin Endocrinol Metab 2008;93:1553-1562.

17 Batista DL, Riar J, Keil M, Stratakis CA: Diagnostic tests for children who are referred for the investigation of Cushing syndrome. Pediatrics 2007;120:e575-e586.

- 18 Martinelli CE, Sader Milani S, Previato JK, Figueira M, Rangel Montenegro AP, MirakiMoud F, et al: Final height in patients with idiopathic short stature and high growth hormone responses to stimulation tests. Horm Res 2007;67:224-230.

19 Savage MO: The combined pituitary function test is not indicated in the routine investigation of short stature. Clin Endocrinol 2000;52: 679.

20 Odeniyi IA, Fasanmade OA: Urinary free cortisol in the diagnosis of Cushing's syndrome: how useful? Niger J Clin Pract 2013;16:269272.
21 Pecori Giraldi F, Ambrogio AG, De Martin M, Fatti LM, Scacchi M, Cavagnini F: Specificity of first-line tests for the diagnosis of Cushing's syndrome: assessment in a large series. J Clin Endocrinol Metab 2007;92:41234129.

22 Elias PC, Martinez EZ, Barone BF, Mermejo LM, Castro M, Moreira AC: Late-night salivary cortisol has a better performance than urinary free cortisol in the diagnosis of Cushing's syndrome. J Clin Endocrinol Metab 2014;99:2045-2051.

23 Alexandraki KI, Grossman AB: Is urinary free cortisol of value in the diagnosis of Cushing's syndrome? Curr Opin Endocrinol Diabetes Obes 2011;18:259-263.

24 Falkner B, Daniels SR: Summary of the Fourth Report on the Diagnosis, Evaluation, and Treatment of High Blood Pressure in Children and Adolescents. Hypertension 2004;44: 387-388.

25 Newell-Price J, Trainer P, Besser GM, Grossman A: The diagnosis and differential diagnosis of Cushing's and pseudo-Cushing's states. Endocr Rev 1999;19:647-672.

26 Storr HL, Chan LF, Grossman AB, Savage MO: Paediatric Cushing's syndrome: epidemiology, investigation and therapeutic advances. Trends Endocrinol Metab 2007;18: 167-174.
27 Newell-Price J, Morris DG, Drake WM, Korbonits M, Monson JP, Besser GM, et al: Optimal response criteria for the human $\mathrm{CRH}$ test in the differential diagnosis of ACTH-dependent Cushing's syndrome. J Clin Endocrinol Metab 2002;87:1640-1655.

28 Lienhardt A, Grossman AB, Dacie JE, Evanson J, Huebner A, Afshar F, et al: Relative contributions of inferior petrosal sinus sampling and pituitary imaging in the investigation of children and adolescents with ACTH-dependent Cushing's syndrome. J Clin Endocrinol Metab 2001;86:5711-5714.

29 Cameron N: The methods of auxological anthropometry; in Faulkner F, Tanner JT (eds): Human Growth. 2. Postnatal Growth. New York, Plenum Press, 1978, pp 35-90.

30 Marshall WA, Tanner JM: Variations in the pattern of pubertal changes in boys. Arch Dis Child 1970;45:13-23.

31 Marshall WA, Tanner JM: Variations in pattern of pubertal changes in girls. Arch Dis Child 1969;44:291-303.

-32 Raff H, Raff JL, Findling JW: Late-night salivary cortisol as a screening test for Cushing's syndrome. J Clin Endocrinol Metab 1998;83: 2681-2686.

33 Gafni RI, Papanicolaou DA, Nieman LK: Nighttime salivary cortisol measurement as a simple, noninvasive, outpatient screening test for Cushing's syndrome in children and adolescents. J Pediatr 2000;137:30-35.

- 34 Arnaldi G, Angeli A, Atkinson AB, Bertagna X, Cavagnini F, Chrousos GP, et al: Diagnosis and complications of Cushing's syndrome: a consensus statement. J Clin Endocrinol Metab 2003;88:5593-5602. 